\title{
ANGIOPATHIA RETINAE TRAUMATICA (PURTSCHER): WITH SOME REMARKS ON PIGMENT MIGRATION
}

BY

\author{
C. H. CHOU, M.D.
}

Department of Ophthalmology, Peking Union Medical College, Peking

THIS very rare condition was first described by Purtscher ${ }^{1}$ in 1910 before the Heidelberg Congress. According to him the fundus change was due to the direct effect of a severe contusion on the head, resulting in a sudden increase of the intracranial pressure, which would extend through the nerve-head to the retinal layer. Haemorrhages observed, followed the rupture of the retinal veins, and white opacities resulted from lymphorrhage. Retinal opacities appeared about six days after the injury and they were situated around the disc, especially along the vessel trunks. These opacities might disappear completely or incompletely in the course of weeks or months.

Since that date a few more cases have been added to the literature. Vogt and Knüsel ${ }^{(2)}$ in 1921 were able to collect ten cases affecting thirteen eyes, including three cases of their own. In reviewing all the cases, Vogt and Kn niisel concluded that the white opacities were mainly located on the temporal side, above and below the disc along the main vessels. The disc and the macular region were exempt. These opacities were round, mostly discrete, but might at times become confluent, of milky to silvery white colour. They were lying in the inner layers of the retina. They appeared to be composed of parallel lines and dots in the direction of nerve fibres in process of absorption. The foci, according to these two authors, were the direct consequence of the trauma, since they were able to observe the typical changes as early as twenty hours after the injury, and as a result of sudden infiltration of lymph fluid between the retinal elements. The limitans interna was wrinkled. In all their cases there was a crescentic scotoma around the fixation point, which was in continuity with the blind spot. The prognosis as to perfect vision is doubtful.

In studying all the cases which have appeared in the literature, I am unable to find a similar case where it is complicated with such pigment change as I have observed in the following case. Besides the extensive pigment migration, it presents also several points of interest.

\section{Case Report}

Peking Union Medical College Hospital, No. 20,302, C.C.T., a boy of 16 years of age, was struck directly on the right eye and the right half of the face by a ball while playing at two o'clock in 
the afternoon of April 30, 1928. He did not fall to the ground or lose consciousness. He felt slight vertigo; otherwise he was quite normal, except that on opening his right eye he noticed loss of vision which lasted for about an hour; then he began to see objects as through a dark cloud. He noticed slight subconjunctival haemorrhage and a small bruise on the right lower lid. There was no bleeding or discharge from the nose, mouth or ear. He

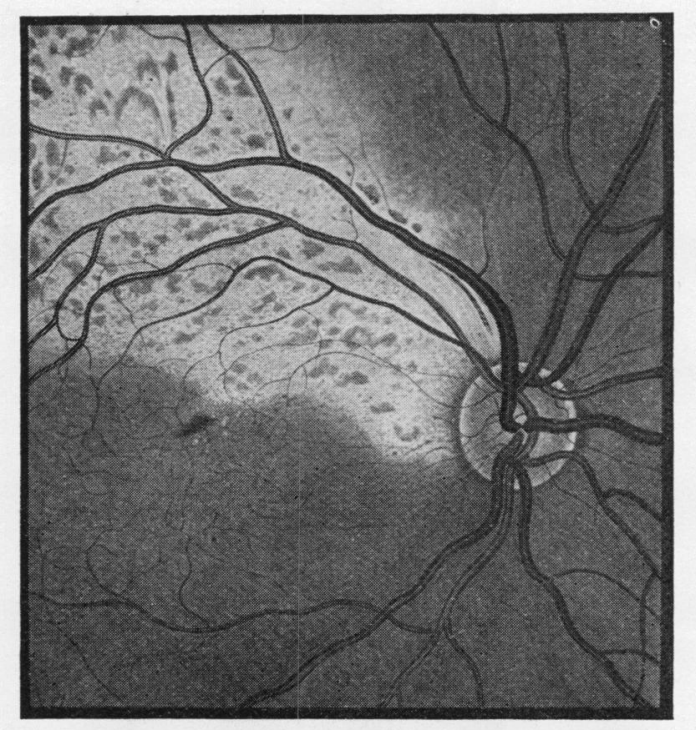

FIG. 1.

O.D. Drawing made two weeks after the contusion The white opaque area is sharply defined. A network of pigment is seen in the deeper layers of the retina, more or less obscured by the opacities. No pigment seen in the inner layers of the retina.

was treated by his college physician and the vision was said to have recovered somewhat. He came to the Peking Union Medical College Clinic on May $\tau$ (a week after the accident). On examination: Vision R.E. 4/30; L.E. 6/4.5.

Externally negative findings except embryontoxon on nasal and temporal sides of both corneae. Pupils equal and regular; reactions normal.

Fundus : R.E.-Disc round, sharply defined. Slight pigment on nasal side of the disc (physiological pigment crescent). Colour of the disc good. On the temporal and superior sector of the fundus was a long narrow patch of opacities extending from the margin of the disc to about 5-6 PD. into the periphery. The width of this patch was about 1 PD. near the disc margin, and became broader 
toward the periphery. The whole patch of opacities was sharply defined, especially on its lower edge and less so peripherally, where it gradually passed into the normal retina. The opacities were of a whitish milky colour and gave more or less an appearance of cotton wool. They were definitely situated behind the retinal vessels, which showed no pathological change even to their end branches. In this opaque area were found numerous aggregations of pigment in various forms and sizes, more or less in the form of a network (Fig. 1). They were rather of grayish colour and situated in the outer layers of the retina, as they were seen through the opaque retina. 'They were probably irregularly arranged pigment

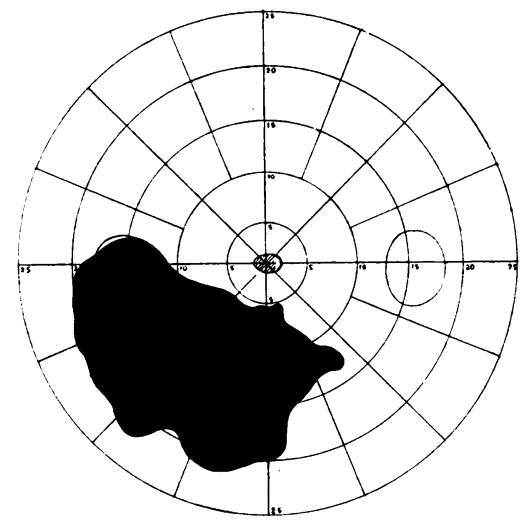

FIG. 2.

Relative central scotoma, and absolute paracentral scotoma for white continuous with the blind spot.

of the pigmented epithelium of the retina. The innermost layer of the retina, the limitans interna, appeared to be wrinkled and showed numerous folds. Over this area of opaque retina the vitreous appeared to be filled with numerous very fine opacities. The macula lutea was of normal colour, and the foveolar reflex was absent. I.E. normail.

On the ninth of May there was noticed a small haemorrhage lying just above, and temporal to the macular region.

On the Bjerrum screen, in relation to the fixation point, there was an absolute scotoma in the temporal lower part of the field continuous with the blind spot. 'This scotoma was smaller than the actual lesion in the retina. A small central relative scotoma for white was also present (Fig. 2).

X-ray examination of the skull showed no evidence of fracture. General physical examination revealed nothing abnormal.

Patient was discharged from the hospital after a week. The vision was improved to $6 / 20$. 
June 6 , about five weeks after the accident, the vision was found to be $6 / 20$.

With $-0.50 \mathrm{D}$. sph. $-0.50 \mathrm{D}$. cyl. axis $180^{\circ} \mathrm{V} .=6 / 12$.

The scotoma showed slight contraction. The fundus picture, moreover, had changed considerably.

Fundus picture on June 6. (Fig. 3).

Disc normal, sharply defined, colour normal. Inside the nervehead, along the horizontal temporal artery and especially along the main superficial vessel trunks, there were numerous black pigment

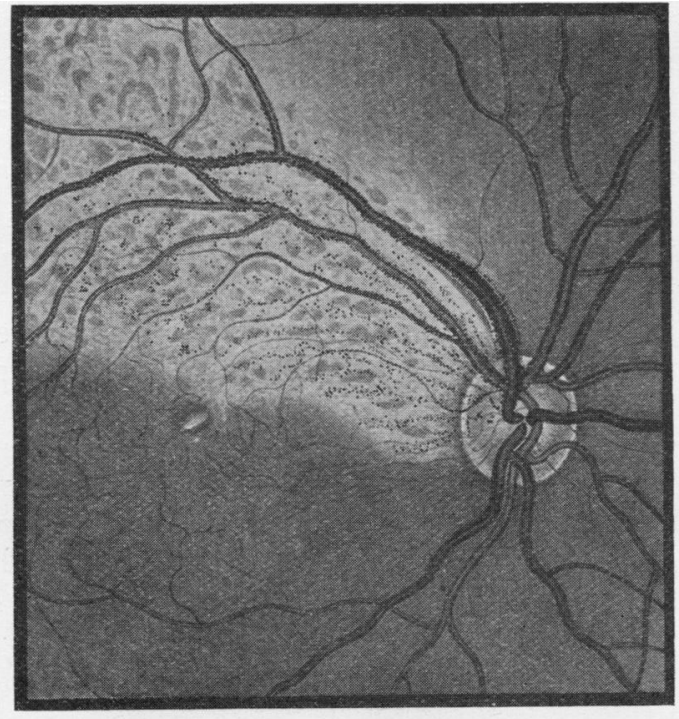

FIG. 3 .

Drawing made five weeks after injury showing the grayish yellow opacities of the retina. Note the extensive migration of the retinal pigment as fine black dots, along the vessels, and also into the papilla. The foveolar reflex deviated upward.

dots, forming black accompanying stripes. They seemed to be separated here and there from the vessel walls by a small space, probably the perivascular lymph space. Some pigment dots were also seen to be free in the temporal and upper quadrant of the nervehead.

The fine vitreous opacities in front of the retinal opacity, which were visible on the last examination had disappeared completely. 'The original white area of retinal opacity had become grayish yellow in colour and more or less wrinkled. The vessels were absolutely normal. Along the superior vessel trunks were numerous fine black dots of various sizes. These black accompanying stripes could be followed to a distance of about 3-4 PD. from the disc margin (Fig. 3). They were now mostly found to be 
a little distance from the vessel wall. Some of them might have been covering the retinal vessels. Besides these accompanying stripes, numerous fine black pigment dots were found. In this opaque area they had the appearance of fine coal-black particles on a grayish background. They were mostly arranged in radial streaks following the retinal nerve fibre layer. No pigment migration was found outside of the opaque area.

In the outer layers of the retina one could see grayish spots scattered all over this opaque area, they formed the last remnant of the original network structure. They were of various shapes and sizes and mostly irregular in arrangement. These were probably the pigmented masses which were situated in the outer layers of the retina and gave a reticular appearance. The pigment epithelial layer of the retina was atrophied and all its pigment had migrated into the various strata of the retina. The choroidal vessels, shining through the now more or less transparent retina, became visible. No pathological changes of the choroidal vessels could be deduced from the ophthalmoscopic examination.

Red-free light examination showed the macula lutea less sharp and larger than it normally should be. There were numerous glistening white dots. The foveolar reflex was white and lay in front of a yellow stripe which was visible in the ordinary light as a sharp line in the upper half of the macula. The foveolar reflex was slightly deviated upward. The nerve fibre layer was normally visible only in the near neighbourhood of the disc. There was no haemorrhage seen anywhere in the fundus.

\section{Discussion}

My case shows many interesting points of which some have not been previously described, and some differed from other reported cases, but the diagnosis of the condition is beyond any doubt.

(1) Trauma: According to Purtscher and others this condition was produced after a severe contusion on the skull. Most of the cases resulted from a fall on the head. In Schneider's ${ }^{(3)}$ case the injury was a compression of the chest. Titze ${ }^{(4)}$ reported a case following compression of the abdomen and trunk with rupture of the liver. In $\mathrm{my}$ case the blow by a ball came directly from the front and struck on the orbit and the right side of the face. I find no other case in the literature where the condition has been produced by this direct contusion on the orbit. Therefore the mechanism may also be different.

Purtscher was of opinion that the fall on the head would compress the spine in its longitudinal direction, and as a result the cerebro-spinal fluid would be forced headward. With this sudden increase of intracranial pressure, the cerebral fluid would find its 
way into the opening of the skull, then through the subarachnoidal space, into the nerve-head, and to the retina. Therefore in all the cases the changes are chiefly around the disc and follow the main vessels. In my case the contusion came directly from the front. The curvature of this ball may have fitted the orbital margin very well. The contusion will be chiefly on the orbit rather than on the eyeball itself. Otherwise we would have seen such typical changes in the eye as luxation of the lens, rupture of the choroid, or retina, corneal opacities, Berlin's opacity, etc., instead of a typical Purtscher's disease. 'The force of this sudden contusion on the orbit will be transmitted to the skull through the optical canal by the compression of the orbital contents, resulting in a sudden increase of intracranial pressure. But immediately after the contusion the eyeball together with the orbital contents will return to their original position. This will create a negative pressure inside the orbit as well as inside the eyeball. The cerebral fluid will, therefore, rush into the eye both by the action of sucking and the previous rise in the intracranial pressure. This gush of cerebral fluid follows the retinal vessels and becomes extravasated into the retinal tissue through the ruptured perivascular lymph spaces. The contusion on the eyeball itself, moreover, may have helped directly by the development of changes in the lymph spaces.

(2) The White Patch: The white patch in the retina in this case is confined to a sector-shaped area following the superior temporal retinal vessels. It forms a single continuous area. No isolated patches are found elsewhere in the fundus. Stahli's ${ }^{(5)}$ was the only other case where the white opacity formed a single continuous patch around the disc. This opaque area is of typical milky colour in its early stage, and the vessels running on its inner surface show no evidence of any pathological change. The opacities are situated in the inner layers of the retina and obscure the changes in the depth of the retina, which appeared to me in the early stage as a network of grayish irregular patches. Opinions vary as to how soon after the trauma this opacity develops. Purtscher set its first appearance on the sixth day after the contusion, while Vogt and Knüsel observed the typical changes after twenty hours. In the present case, when the patient came to me a week after the injury, I observed the condition had already been well established, and further observation only showed the stages of retrogression. In nearly all the cases reported there was a sudden change of vision immediately after the accident; this is also true of $\mathrm{my}$ case. This sudden loss of vision immediately after the blow in my case, which recovered somewhat after an hour, may be simply a shock of the nerve fibres; beyond that I am not able to say whether it is actually due to the opacities or haemorrhages in the eye. 
The white patches invariably become absorbed in the course of time and may leave absolutely no trace of former change in the fundus. I would have seen the same result were there no pigment migration in my case. In five weeks' time the colour of the opaque area has changed from a milk white to a grayish yellow. This change, the absorption of the lymph in the nerve fibre layers, enables me to see more distinctly the changes in the deeper layers of the retina.

Considering the slowness in its absorption and the normal appearance of the retinal vessels, and further, the direction of the extension of the opacitics following the nerve fibres this condition should not be confused with the more frequently observed Berlin's opacity, which is produced by a direct contusion on the eyeball. Best, ${ }^{(6)}$ however, considers there is no essential difference between Purtscher's disease and Berlin's opacity. He explained the opacities in Purtscher's disease as the result of an invasion of tissue fluids and serum into the new paths by means of fine streaks in the retina and vessel walls. In studying the clinical course and the mechanism of the trauma, the hypothesis of Purtscher supported by Vogt and Knüsel seems to be a better explanation. The sudden infiltration of the lymph between the retinal elements by such an injury would be a reasonable consequence.

(3) Pigment migration: This is the most interesting point in this case.

As the extravasation became absorbed the network of grayish patches which were observed during the early stages proved to be irregularly arranged masses of pigment from the pigmented epithelial layer of the retina. The colour of these reticular masses varied from time to time and they arranged themselves in different sizes and shapes. They were also situated in various layers of the retinal elements. That the pigment was not haematogenous in origin is proved by the fact that there was no clumping of pigment masses as after haemorrhage, nor was any haemorrhage within the area of opacity found during the whole four weeks of observation.

This pigment migration is fairly uniform all over the opaque area, and presents a dark gray network in a yellowish gray background. Such more or less uniform pigment disturbance can find its explanation only in migration from the pigmented epithelial layers of the retina. They are not derived from the choroidal pigment, the colour of which is never so black as that which I have observed in my case. The study of the pigment on the innermost layers of the retina will certainly give further proof of this hypothesis. Here I find the pigment consists of fine black dots, most of them single, but here and there forming tiny masses. They are scattered in the nerve fibre layer, and in the neighbourhood of the disc, and arrange themselves in radial streaks following the direction of the 
nerve fibres. The pigment along the vessels forms accompanying stripes, they are apparently situated a little distance from the vessel walls, as they are separated by a clear space, probably the perivascular lymph space. The migration of pigment is especially marked in these regions along the vessels and extends into the optic nerve-head. They are characteristic as being single, fine, coal-black dots. Some of them may have been on the surface of the retinal vessels.

Why the pigment of the pigmented epithelial layer of the retina shows so extensive migration in this case is difficult to explain. The fact that the deposition of pigment is most marked in the immediate vicinity of the retinal vessels may point to a marked change in the perivascular lymph spaces which caused the extravasation of the lymph into the retina. This may give rise to a disturbance in nutrition of the vessel walls. Krückmann, ${ }^{(7)}$ who has made a most complete study of the question of retinal pigments, found that migration of pigment to the vessel walls is frequently met with, and that the pigment is usually taken up by the proliferating glial fibres. In our case the severe damage following the change in the perivascular lymph spaces would induce an active proliferation of the glial tissue. These fibres would then take up the migrating pigment which has been expelled by the degenerated pigment epithelial layer. This deposition of pigment on the wall of the vessels may sometimes lead to a sclerosis of the retinal vessels. I have not observed such changes as white accompanying stripes, narrowing of the vessel walls, etc., in $\mathrm{my}$ case. These sclerotic changes, however, may not be present in this particular case.

At this stage of the disease the condition might be confused with a retinitis sclopetaria had the case not been followed from the beginning. A case of old retinitis sclopetaria following a severe blow on the eye many years previously, described in DimmerPillat's ${ }^{(8)}$ book, shows many points of similarity. On the other hand the condition, so-called retinitis sclopetaria, is the result of a severe retinal haemorrhage, which may be intraretinal or preretinal or retroretinal. Therefore the pigment change is invariably haematogenous in origin. From the clinical observation I have never been able to find haemorrhage in this area of opacity in my case, so I can conclude that this condition has nothing to do with retinitis sclopetaria; nor have I found any evidence lof inflammation. The pigmentary change has to be explained on a non-haemorrhagic and a non-inflammatory basis.

With regard to the question of pigment migration, many theories have been advanced, but is real aetiology is very obscure and leaves much ground for dispute. It has been a known fact since Müller and Leber, that the pigment epithelial layer together with the outer 
layers of the retina depend on the choroidal capillaries for their nourishment. Wagenmann ${ }^{(9)}$ ! by means of pathological examination of human eyes, believed that the changes in the pigment epithelial layer of the retina could be produced only by disturbance of the circulation in the ciliary vessels. Suganuma ${ }^{(10)}$ experimenting on rabbits' eyes obtained a regressive change consisting of a migration of the pigment granules, which were taken up by the proliferating glial fibres, and Müller's supporting fibres. He could produce this result only by section of the short posterior ciliary arteries or by introduction of an iron splinter into the vitreous body.

Wagenmann quoted a patient of 23 years of age who received a blow on the eye with a billiard cue. One day later showed protrusion of the eyeball with limitation of movement. Ophthalmoscopic examination showed swelling of the edges of the disc and retinal opacities, most marked in the macular region. Arteries and veins bloodless, periphery of retina pale. The retinal opacities disappeared after forty days. Vessels filled again somewhat, circulation questionable. Vessels remained narrow. Marked pigment changes observed, especially in the macular region. It showed a diffuse discolorization of the pigment epithelium with migration of pigment into the retina. About six weeks later the change came to a standstill. The arteries and veins, except in the neighbourhood of the disc, were completely invisible. The fundus in the upper and lower temporal parts was diffusely discoloured, and the stroma pigment of the choroid was atrophied. The retinal pigment, to great extent, migrated into the retina. Only the nasal and upper nasal parts of the retina were normal.

In my case typical localised regressive changes of the pigment epithelium with migration of the pigment into the various layers of the retina is to be seen. This change is sharply limited to the upper temporal quadrant. This area corresponds to the opaque part of the retina where I could not find any haemorrhage or any signs of inflammation. The vessels are absolutely normal. I can rule out with certainty that the condition is produced upon an inflammatory basis. The changes, however, are quite similar to the changes in animals after the severing of the short posterior ciliary arteries. Whether such is the aetiology in my case cannot be stated with certainty. It seems rather unlikely that a contusion on the orbit would lead to a selective severing of some short posterior ciliary arteries. Wagenmann was also in doubt whether this was the case in his patient.

In reviewing the literature I find that $\mathrm{Zirm}^{(11)}$ explained a case of macular pigment change as a result of an extensive central haemorrhage in the retina, and the pigment as a product of the haemorrhage and the residuals of the reactive inflammation around the necrotic part of both maculae six months after looking directly 
into the sun for a few minutes; although he did not see the haemorrhages himself. Moreover it is not known whether or not sunlight burn will cause an actual haemorrhage or inflammation in the retina. Furthermore, the pigment changes seen after a haemorrhage will give an entirely different picture. The pigment changes which Zirm has observed also seem to fall into the same category as my case, where the pigment migration is caused neither by a haemorrhage nor by inflammation of the retina and choroid.

Recently Bedell ${ }^{(12)}$ published a photographic history of a traumatic retino-choroiditis in a boy of 15 , who was struck over the left frontal region by a phonograph record. He observed marked oedema of the retina, and the typical migration of retinal pigment began about seven days after the accident. During his whole observation of five and a half months he found the migration of pigment increased with considerable thinning of the retina. The pigment appeared as coal-black flecks and was scattered all over the region of a previously oedematous retina. This case stands very close to my case, where the pigment migration was caused only by trauma.

The explanation of this migration of pigment into the retinal layers may therefore fall within the following three possibilities :

(a) There is a primary change in the chorio-capillaris. This may be caused by a direct contusion of this part of the choroid, so as to produce such changes in this layer that the nutrition to the outer layers of the retina, particularly the pigment epithelial layer, is greatly disturbed. The migration of the pigment in this case will be more or less similar to the condition following section of the short posterior ciliary arteries. Miarie Huguenin ${ }^{(13)}$ collected from the literature eleven cases of pigment migration following a contusion by a blunt object. She believed that this change was produced by a laceration of a ciliary artery. This was, however, only theoretically deduced from Wagenmann's experiment on rabïits.

(b) The retinal glial supporting apparatus, which probably maintains the equilibrium of nutrition of the retina, may be damaged.

(c) Lastly, the pigment epithelial layer of the retina itself may have been injured by the direct contusion on this particular area of the fundus.

(4) Haemorrhage: I observed only a small haemorrhage above the macular region, outside of the opaque area, which became absorbed in a few days. In view of the fact of the rapidity of the absorption, more haemorrhages might have been present in the fundus, and no trace have been left when I examined the patient. 
Therefore, the absence of extensive haemorrhage in my case does not disprove its occurrence.

(5) Vitreous Opacities: The finely-dotted vitreous opacities which I observed over the area of the opaque retina may have been the last remaining part of vitreous haemorrhage; as they disappeared entirely only a few days after the first examination.

(6) Scotoma: A paracentral absolute scotoma is here also present. It corresponds closely to the retinal change. The scotoma shows practically no alteration after four weeks' interval. It will be more or less permanent. A small central relative scotoma is also present. It may be explained by the presence of oedema of the macular region. Whether this scotoma will be permanent or not, it is impossible to say. The prognosis in my case, as far as perfect recovery of vision is concerned, is rather poor.

\section{Conclusions}

(1) After a direct contusion on the right orbit and face by a ball, there was produced a typical case of Purtscher's disease involving the upper temporal part of the retina along the superior temporal vessels, extending from the disc margin to a distance of about 5-6 PD. into the periphery.

(2) There were present a paracentral scotoma and a small central relative scotoma. 'The former after four weeks' observation showed practically no change in size, and will probably be permanent.

(3) A marked pigment migration into the various layers of the retina in this affected area, was observed about five weeks after the injury. The colour of the affected area has changed from milkv white to grayish yellow, which is probably the colour of the depigmented pigment epithelial layer of the retina.

I wish to express my hearty thanks to my chief, Prof. A. Pillat, for his valuable suggestions and help in preparing this paper.

\section{BIBLIOGRAPHY}

1 Purtscher (No. 1).-Noch unbekannte Befunde nach Schädeltrauma. Ber. der Ophthal. gesellschaft, Heidelberg, S. 294, 1910.

(No. 2.)-Angiopathia retinae traumatica, Lymphorrhagie des Augenhintergrundes. Arch.f. Ophthal Bd. LXXXII, S. 347, 1912.

2. Vogt and Knüsel. - Die Purtschersche Fernschädigung der Netzhaut durch Schädeltrauma. Klin. Monatsbl.f. Augenheilk., Bd. LXVII, SS. 512-536 1921.

3. Schneider.-Purtschersche Fernschädigung der Netzhaut nach thorax kompression. Klin. Monatsbl. f. Augenheilk., Bd. LXXII, SS. 116-119, 1924 .

4. Tietze.-Quoted in Leber's Hand-book. Handbuch der Augenheilk. Die Krankheiten der Netzhaut, 2 Aufl., Bd. VII, S. 1336.

5. Stahli. - Zur Kenntnis der Angiopathia Retinae traumatica. Klin.Monatsbl f. Augenheilk., Bd. LV, SS. 300-307, 1915.

6. Best.-Commotio Retinae als Fernwirkung Klin. Monatsbl. f. Augen heilk., Bd. LXIII, SS. 578-580, 1919.

Die Entstehungsursache der Purtscherschen Fernschädigung der Netzhaut durch Schädelverletzung. Klin. Monatsbl. f. Augenheilk., Bd. LXVIII, SS. 725-729, 1922. 
7. Kruckmann.-Pigmentierung u. Wucherung der Netzhautneuroglia. Arch. f. Ophthal., Bd. LX, SS. 452-512, 1905.

8. Dimmer-Pillat. - Photographie der Fundus. Pl. 57, Fig. 1.

9. Wagenmann.-Experimentelle Untersuchungen über den Einfluss der Circulation in den Netzhaut; und Aderhaut-gefässen auf die Ernährung des Auges, insbesondere der Retina und über die Folgen der Sehnerven Durchschneidung. Arch.f. Ophthal., Vol. XXXVI, SS. 1-120, 1890.

10. Suganuma. - Ueber die pathologischen Veränderungen der chorioidealen Glashaut und des retinalen Pigmentepithels. Arch.f. Ophthal., Bd.CXV, SS. 87-128, 1924.

11. Zirm. - Ein Fall von bleibenden ausgedehnten Veränderungen der beiden Maculae durch direktes Sonnen-licht. Arch. f. Ophthal., Bd. LX, SS. 401-404, 1905.

12. Bedell.-Photographic history of a traumatic retino-choroiditis. Arch. of Ophthal., Vol. LVII, pp. 262-264, 1928.

13. Hugu nin, Marie. - Traumatic rupture of the ciliary arteries. La Clin. Ophtal., février, 1916. Abstracted by Thomson in Brit. Jl. of Ophthal. Vol. I, p. 99, 1917.

\section{CONCOMITANT STRABISMUS AND HETEROPHORIA}

BY

Kenneth R. Smith, M.D., B.S.(Lond.)

LATE ROYAL AIR FORCE MEDICAL SERVICE

\section{Children's Squint and Heterophoria}

THE meaning of the term heterophoria given by Mr. Hartridge is "a disturbance of the equilibrium of the muscles of the eyeball." The defect of sight which bears the same name in the flying community is an occasional failure of binocular vision. Sight with both eyes together is apt to break down, and then that of one eye only is used instead. Air pilots and those learning to fly, who have this defect, make bad landings and are apt to crash, because they are unable to judge their distance from the ground when they wish to land. They are quite conscious of the failure and sometimes say that "they do not know where they are when they come near the ground." They are put through a course of training to render their binocular vision more stable and constant; if then they lose the defect, they may become excellent pilots.

Similarly in reference to squint: "Strabismus exists where there is deviation in the direction of the eyes, so that the visual axes are not directed to the same object," is the definition given by Mr. Hartridge. No mention is made of defect of vision; and this definition includes pathological conditions remote from those of ordinary cases of children's squint. Yet no case of children's squint ever existed at one and the same time with binocular vision : all signs of squint disappear when binocular vision is restored, and 